may be seen within a few steps of South-place, either at the cottages behind the "Prince of Wales" public-house, or at Mechanic's-court, near the Castle. Here the pans are clean, the traps full of clear water, and no odour prevailing; but these closets have a suitable waste-preventer and a twogallon flushing apparatus. What has been done here can with equal facility be done elsewhere, if the authorities only insist upon it.

In Sidney-place we also saw much wretchedness and bad sanitation. Here the houses have very narrow back yards, unflushed closets, and uncovered dust-heaps. The stench is naturally blown into the smashed windows of the basements of the houses, and from thence is drawn by the heat into the upper rooms through the dilapidated flooring. On entering some of these rooms we encountered a very fetid odour, and the walls were smeared with crushed vermin In one room a bed had fallen through the ceiling, so rotten was the structure of the house; and here a poor woman resided with her husband and six children. They had two rooms, two beds, hardly any bedclothes, and no furniture. The husband earned fifteen shillings a week, the woman was too ill to help, and they had to pay five shillings rent. The soil-pipe of a linendraper's establishment next door joins on to the closet of this miserable abode, and sometimes. this one pipe becomes so clogged that the soil comes up through the gully trap in the little yard outside the closet door. A boy in this house, we were informed, has had scarlet fever, and a girl next door died of the same complaint.

Similar harrowing details might be given concerning other slums of Windsor: Clarence-clump, Love-lane, some of the courts off Peascod-street, Prospect-mews, \&c. The details of the number of houses, the insufficient supply of closets, and the total absence of water will be found in the recent reports of the borough surveyor. The medical officer of health, in one of his reports, thus describes Prospect-mews:- "Wheeler has two rooms, one of which, being without fireplace and having about 760 feet cubic space, though with two windows, was occupied by five persons. The other, a small room, was used as a day room, and at night by two persons. Edwards has two sleepingrooms, with about 578 and 681 cubic feet space respectively, the latter having no fireplace. The family number eight persons. They have also a very poor room in another house, used as a day room, and not available as a sleepingroom. His family have been suffering from scarlet fever, and are paupers. The dwellings in Prospect-mews are not suitable for occupation by families, and ought not to be let for that purpose."

This was written a year ago, but nothing has been done to improve the place, though the mayor's private house faces the entrance to the mews. Close by, also, in the main street, there has been a death from typhoid fever during the last week of July this year. We carefully examined this, a higher class house, and for which an annual rent of $£ 24$ is paid. The closet, in the back garden, had formerly been supplied with water, but the water was now carefully cut off! In the basement there is a sink with a huge three-inch open and untrapped pipe. A bell-trap in the centre of the floor was quite dry, and allowed the escape of very foul effluvia. Within a dozen yards of this house there is a large boys' school, and the other neighbouring dwellings are inhabited by married soldiers and their families. Indeed, there is much to be done at Windsor with respect to the drainage of the better class of houses, which are let at $£ 40$ to $£ 50$ a year. In the suburbs of Windsor the villa and country residences have cesspools, with overflows into the open ditches. This is notably the case at Spital. The water in the ditch of Clewer-house-lane is quite black, and we received numerous complaints of the abominable nuisance this occasions. The Bourne ditch is a still greater annoyance and danger, for it runs right through Windsor. Two handsome villas have remained unlet for seven years because of their proximity to this ditch. The persons who live in the houses a little further off complained to us of sore-throats, fever, rats, and bad smells. We are also assured that there have been recently seven cases of diphtheria at Windsor, one ending fatally. The medical man in attendance attributed this latter case to the Bourne ditch, which passed close by the patient's house.

Another grave defect in Windsor sanitation is the fact that the whole of King's-terrace and several other cottages are built below high water mark. It is therefore not only extremely difficult to drain this district and to prevent dampness, but the quarter is subject to very serious floods. On one occasion the whole district was under water, which rose to the height of about three feet in the parlours. The contents of the closets were of course brought up with the water and distributed over the entire terract. The houses could only be approached in punts. Naturall? the quarter is unwholesome, and we found that a severe epidemic of measles had attacked the entire terrace. In every house we entered the same melancholy story was told us. At No. 23 and No. 24 all the children were down with measles. At No. 21 six children had suffered from the same cause, and the inhabitants pumped up slugs with their drinking-water-for wells are allowed in this low-lying and dangerous district. Under such circumstances an outbreak of cholera would surely prove most fatal in King's-terrace. The closets, the wells, the sinks, the gullies that carry of the slops, are all within a few feet of each other, and constructed in the damp soil below the river level. Building under these conditions should not have been authorised.

Of the general drainage--that is, the sewers of Windsorwe cannot say much. The absence of the borough surveyor prevented our obtaining full details. Considering the number of complaints made of smells emanating from the sewers, we should imagine they were insufficiently flushed. The communications from the gutters to the sewers are trapped, and Baldwin's ventilators placed in the centre of the street. There are twenty-two flushing stations, which provide a 1000-gallon flush. The flush is discharged three times a week at two stations, twice at two other stations, and only once a week at the remaining places. This especially in dry weather, we should imagine to be altogether insufficient, particularly when we bear in mind the large number of closets that have no water at all. In dry weathen at least, we would recommend automatic flushing tanks, dis. charging their contents every two hours.

Much more could be added concerning the sanitation of Windsor, particularly if we described in full the condition of the better class of houses, and criticised the general engineering details of the sewers and the treatment of the serrage at the sewage farm. We might also examine and explain the apparently small death-rate of the town. This is in all probability due to the very low birth-rate, the small number of children, and the presence in the population of an exceptionally healthy element-namely, soldiers, their families, and the attendants at the Castle. In spite, however, of this particularly favourable circumstance, the town is specially open to the danger of epidemic disease; and, considering the possible advent of cholera, we have said sufficient to shor that there is urgent need of energetic sanitary reforms in the Royal borough of Windsor.

\section{ENTERTC FEVER AT THE WEST LONDON DISTRICT SCHOOL.}

By Peter W. Delamotte, M.R.C.S. ENa., MEDICAL OFFICER TO THE sCHOoL.

IN The LANCeT of August 1st mention is made of a serious outbreak of enteric fever at the West London District School at Ashford, and that there are no satisfactorg statistics of the health and mortality in these sorts of schools. In the same issue is an interesting contribution on "The Relation of Typhoid Fever to the Level of Subsoi Water"; it is to this relation that I am desirous of adding some decided evidence condemning subsoil water, and to record what has taken place at the school. Your obserpar tions referring to the health and mortality of the children in this school I can vouch for, and feel sure of both comparing favourably, considering the class of children, with any other institution of its size, be it pauper or private; on this question I hope to be able to render an account at some future date, when more time is at my disposal.

The object of this report is to give briefly a few facts it connexion with this very serious outbreak of enteric fererin its relation to the water-supply. My remarks may be ppefaced by stating that the building is situate on a grarel solu and its surrounding grounds are on a dead level with a garat subsoil. The school was opened in 1872 , and is certifed to accommodate 790 children, from the ages of three years to 
sirteen, of both sexes. The earth-closet system is in use throughout the building for all excrementitious matter, with the exception of one watercloset at the engineer's, discharging itself into the general system. The closet is within ninety feet of the well. The present drainage system came in to operation in December, 1883, and is of the same kind as that of Eastbourne-namely, the "Shone system," being a continuous distribution of the sewage minus the excrement, except in one instance that I have already mentioned. This new sewerage extends to land not previously irrigated, and may account for the small number of cases in 1884. The system adopted before the Shone was to collect the sewage in a tank and then pump it on to the ground. The old sewers are made use of occusionally in dry weather. The sewage irrigation has been going on since the school was opened, but not in any part of the grounds where the children are allowed their pastime, or in the vicinity of the well. A few cases of abortive typhoid and typhoid fever have arisen from time to time, but not in sufficient numbers to cause suspicion that the water was contaminated, though it was analysed and pronounced to be fit for drinking purposes. The number of cases of enteric fever in 1881 was three, in 1882 two, in 1883 twenty-one, and in 1884 five. Professor Corfield visited the school in February, 1882, and reported that the position of the sewage tank and the boys' earth-closets were probably the cause of the sporadic cases; most of them arose on the boys' side of the building, and it was anticipated that as soon as the tank was removed and the closets improved upon enteric fever would have disappeared, but still cases occasionally arose. The water was again analysed and reported to be fit for drinking; therefore, as far back as 1882, every effort was made by the managers and their officers to discover and remove the cause, butwithoutavail, From the beginning of March, 1885, to about the third week in March, the school was free from typhoid. Towards the end of the month one or two cases were admitted. The engineer and some of his family were attacked; they reside in the engine-house, about eighty or ninety feet from the well. The medical attendant did not at first diagnose enteric fever, and the excreta were disposed of in this the only watercloset. The ground over the site of the old sewage tank had been dug up and planted with trees, and there had been continued dry weather. Dr. Bridges, Local Government Board inspector, advised that the water should be again analysed. Six samples of the same water were talien from various parts of the building after a heavy rain on June 9th, and on the 18th of the same month Professor Heaton, of Charing-cross Hospital, reported, after giving a quantitative analysis, as follows: "These waters resemble one another closely, and have evidently had a common origin. Unfortunately all must be condemned absolutely as drinking-water; for although the total solids, chlorine, free ammonia, and nitrogen are not excessive, and the albuminoid ammonia moderate in all but Nos. 1 . and 5 , the presence of phosphates in considerable quantities, the bad smell of the water and ignited residue, and, above all, the great number of living and dead bacteria, point the waters out as eminently dangerous." Steps were at once taken to boil and filter the water until a supply from a wholly different source could be obtained. The well from which the school was supplied is close to the engine-house, is twenty feet deep, sunk in a grarel soil lined with iron cylinders bolted together, and four feet in diameter. No direct contamination could take place from any material passing in at the sides. The distance from the top of the well to the water is eight feet, leaving twelve feet of water; this is lowered to the extent of one foot within five minutes after the steam pumps are set in motion, and remains at this level after pumping the daily requisite quantity, 25,000 gallons. Within five minutes after the pumps cease the water rises to its former level. It may be inferred that this well must drain a large subsoil area, considering the large quantity (25,000 gallons) daily taken from it; and it would appear it must have drawn water from parts of the ground where irrigation by sewage Was going on. Though previous analysis failed to detect impurities, there cannot be much doubt, after Mr. Heaton's report, that the water in some way was the cause of these sporadic cases

The present outbreak occurred in June and July, affecting nearly 250 children, causing six deaths. It may be concluded from Professor Heaton's report, the large number and the sudden way in which they were attacked, that either some typhoid contagium entered the water, or else, from the continued dry weather and the heavy rain following, this subsoil water became still more polluted and gave rise to this serious outbreak. I'robably it is only occasionally that the water becomes polluted, and it had been observed by me that cases arose after a fall of rain. In the former analysis of the water no particular time was fixed upon to take samples, and the large and never-failing quantity made use of tended rather to make one think the water to be of a wholesome character. On June 18th the children were cautioned not to drink any water but the boiled and filtered; and it was not until the water was entirely cut off that the cases of fever rapidly decreased. The water is now obtained from a water company.

The period of incubation cannot be fixed, and the probabilities are that the cases were already incubating before the boiling and filtering took place. The patients, with one or two exceptions, are doing well ; some are convalescent, and others fast approaching it. They are all treated in large, well-ventilated wards, under sisters and trained nurses, both day and night. Mr. F. J. Warwick, M.B.Cantab., has been appointed assistant resident medical officer pro tem. It is not for me to theorise about the cause of the outbreak, as it is self-evident. The water was a never-failing supply in the driest weather, and 25,000 gallons a day had been pumped from the bottom of this twenty-feet well in a gravel soil for upwards of fifteen years, supplying 800 or 900 people. Analysis had never detected any impurities up to a certain date. It had caused no epidemic; but given two dry consecutive summers, then a few hours' rain, and this previous pure and never-failing water becomes highly dangerous, as proved by Professor Heaton. No accumulative cesspool filth could have been washed into the well, as in the Terling epidemic; but that sewage did get in, and that it must have entered at a distance varying from 100 feet to 100 yards, and must have been drawn into the well through the gravel, is without doubt.

\section{颗armacologgr and Tlyerapentics.}

STROPHANTHUS HISPIDUS.

WE understand that Dr. Fraser, Professor of Materia Medica in the University of Edinburgh, is about to publish the result of his researches on the physiological action and therapeutic uses of the "kombé arrow poison" (Strophanthus hispidus), a subject which has engaged his attention for nearly fifteen years. The plant is a woody climber growing freely in the forests both of the mountains and valleys of many parts of Central Africa. In the Manganga country near the Zambesi, it is known as kombé, but in the Gaboon district it is called " inee," "onaye," or "onage." It climbs the highest trees, hanging from branch to branch in graceful festoons like a wood vine. Its flowers are pale yellow, and last only a very short time during the weeks which immecliately precede the rainy season. The fruit ripens in June, and is collected by the natives with much care and many mystic ceremonies. From the seeds is extracted a juice in which is dipped the points of the arrows used for shooting wild animals. Dr.Livingstone, in his well-known narrative of the expedition to the Zambesi, refers to its employment in this way, and says that the poison is so deadly that a beast on being struck at once falls to the ground paralysed. The follicles, specimens of which we have examined, are about a foot in length, and contain from 150 to 200 seeds, each bearing a beautiful delicate plumose appendage mounted on the extremity of a thread-like stalk some three or four inches long. From the seeds Dr. Fraser has succeeded in extracting a principle of very great activity which he has named "strophanthin." When examined under the microscope, it is seen to be composed of myriads of delicate interwoven crystals of all shapes and sizes. Injected under the skin of a frog, it arrests the action of the heart, causing complete stoppage of that organ, the ventricle being found pale and contracted, whilst the auricles are dark and distended. There seems to be little doubt that it acts directly on the cardiac muscular fibre. In physiological action it is allied to digitaline, the active principle of the common foxglove, although it exceeds it in activity, and differs from it in many important particulars. It is probable, too, that it is related to antiarin, the poisonous principle of the deadly upas tree of Java. We believe that Professor Fraser has succeeded in laying down 